I was merely concerned to report these cases, which I had found of interest, and to point out that though they diftered considerably in clinical appearance each was monocular, chronic in course, and revealed similar non-specific changes on biopsy.

The list of conditions which Major Wright indicates may be included in Parinaud's oculorglandular syndrome lends support to his view that this syndrome is liberal in its clinical confines; it would seem that such a label can add little information to a particular case.

I took as my guide to Verhoeff's leptothicosis conjunctivae his original paper published in 1918. As. I pointed out, the special staining for the organism was not carried out but the clinical course and pathological findings for my cases were so dissimilar from the Author's description that I felt justified in excluding this diagnosis.

Major Wright mentioned that the first of my cases had been previously under his care and I would like to correct any implied discourtesy in not having acknowledged this fact. Any chronic recurrent disease in a service patient tends to gravitate to a number of Army Medical Centres. It happens that the four cases under discussion were seen by one or more colleagues, to have referred to each of whom would have burdened unnecessarily a paper of small scope.

Yours, etc.

E. F. KING.

Major, R.A.M.C.

January, 1943.

- This correspondence is now closed-EDITORS.

\title{
THE VERTEBRATE EYE
}

To the Editors of The British Journal of Ophthalmology.

DEAR SiRs,-I have not seen the volume by Dr. Gordon Lynn Walls, "The Vertebrate Eye and its Adaptive Radiation," but I - have read the review published in the December number of the British Journal of Ophthalmology.

In fairness to the author I hasten to challenge the following unwarranted comments made by the reviewer. The statement that "it is certainly the ciliary epithelium covering the ciliary folds and processes" which is the immediate source of the intra-ocular fluid (p. 371) is misleading in the light of recent research, and is indeed rather surprising as emanating from a comparative physiologist.

My personal acquaintance with the Vertebrate Eye is limited to mammalia. In this field and on this subject under discussion; the 
most recent contribution, to my knowledge, is my paper, "The Mechanism of Aqueous Secretion in Mammalia," which appeared in the British Journal of Ophthalmology in January, 1941. Your reviewer has obviously not made himself acquainted with the demonstration presented there, for his criticisms and strictures are not only ill-judged but illuminated by prejudice and not by the light of reason.

$$
\text { I am, etc., }
$$

THOMSON HENDERSON.

15. THE ROPEWALK, NOTTINGHAM. January 15, 1943.

\section{MACULAR HOLE.}

To the Editors of THE BRITISH JOURNAL OF OPHTHALMOLOGY.

DEAR SIRS,-May I report another case similar to that described by Lieutenant Commander Pittar?

R. A., aged 13, attended a school clinic on Nov. 4, 1942, complaining of a black spot in his right vision. Vision was $6 / 126 / 5$, the eyes emmetropic. There was oedema of the right macula. Thinking it might be an early central choroiditis I treated him with atropine and rest. The oedema gradually subsided, being replaced by an appearance of abnormal redness. About this time the boy's mother suggested that the trouble might be due to his having looked at the sun without protection.

On Dec. 30, there was a definite macular "hole" with clean cut edges, though vision was 6/18. This retention of fair vision is surprising, but one occasionally meets it in cases of old central choroiditis in which the ophthalmoscopic appearance suggests a total loss of central vision. No doubt it will deteriorate further.

Yours truly,

18, WIMPOLE STREET, w.1

\section{H. Douglas Smart.}

\section{SYMPATHETIC OPHTHALMITIS}

To the Editors of THE BRITISH JOURNAL OF OPHTHALMOLOGY.

DEAR SIRS,-On p. 572 of your Journal for December, 1942, a letter from Mr. T. Harrison Butler is published in which is described a case supposed to be one of sympathetic ophthalmitis. The interval of time between the date of excision of the exciting eye and that of the first signs of inflammation in the sympathising eye was 